\title{
Distinct expression and prognostic value of members of the epidermal growth factor receptor family in ovarian cancer
}

This article was published in the following Dove Press journal: Cancer Management and Research

\section{Quan Zhou* \\ Chao-Nan Hou* \\ Huai-Jie Yang* \\ $\mathrm{Ze} \mathrm{He}$ \\ Man-Zhen Zuo}

Department of Gynecology and Obstetrics, The People's Hospital of China Three Gorges University/The First People's Hospital of Yichang, Yichang 443000, China

*These authors contributed equally to this work
Correspondence: Quan Zhou

Department of Gynecology and Obstetrics, The People's Hospital of China Three Gorges University/The First People's Hospital of Yichang, 2, Jie-fang Road, Yi Chang 443000, Hubei, China

$\mathrm{Tel}+86$ I50 9092 I5I2

Fax +8607176287704

Email zhouquan8519@163.com
Background: Increased aberrant expression or activation of the epidermal growth factor receptor ( $E G F R$ ) family members has been reported in a wide range of cancers, and the EGFR family of tyrosine kinases has emerged as an important therapeutic target in malignancies. However, the expression patterns and exact roles of each distinct EGFR family member, which contribute to tumorigenesis and progression of ovarian cancer (OC), are yet to be elucidated.

Materials and methods: In the current study, we report the distinct expression and prognostic value of $E G F R$ family members in patients with $\mathrm{OC}$ by analyzing a series of databases including ONCOMINE, Gene Expression Profiling Interactive Analysis , Kaplan-Meier plotter, cBioPortal, and Database for Annotation, Visualization and Integrated Discovery .

Results: It was found that in patients with OC, mRNA expression levels of $E R B B 2 / 3 / 4$ were significantly upregulated, whereas the transcription levels of $E G F R$ were downregulated. Aberrant $E G F R$ expression and $E R B B 2 / 3 / 4$ mRNA levels were associated with OC prognosis.

Conclusion: These results suggest that $E G F R$ and $E R B B 3 / 4$ are distinct prognostic biomarkers and may be potential targets for OC. These results may be beneficial to better understand the molecular underpinning of OC and may be useful to develop tools for more accurate OC prognosis and for promoting the development of EGFR-targeted inhibitors for OC treatment.

Keywords: EGFR, ovarian cancer, database mining, prognostic value, bioinformatics analysis

\section{Introduction}

Ovarian cancer (OC) shows the highest cancer-related death rate among gynecological malignancies, with an estimated 204,000 cases and 125,000 deaths annually worldwide. ${ }^{1,2}$ Over $75 \%$ of patients are not diagnosed until the disease is advanced (stages III and IV). Current prognostic factors do not allow reliable prediction of response to chemotherapy and survival for individual OC patients. The poor rate of survival and the high rate of lethality are partly due to lack of effective biomarkers for prognosis. Therefore, there is a pressing need to find reliable predictive biomarkers for prognosis and to develop novel therapeutic strategies for OC patients., ${ }^{2,3}$

The epidermal growth factor receptor $(E G F R)$ tyrosine kinase family consists of four members: $E G F R, E R B B 2, E R B B 3$, and $E R B B 4$. These receptors are activated when a ligand binds to their extracellular ligand binding domain, which triggers receptor homodimerization or heterodimerization, resulting in the activation of several downstream cell signaling pathways and ultimately in tumor cell proliferation, reduced apoptosis, and tumor migration and invasion. ${ }^{4-6}$ In the past three decades, increased aberrant expression or activation of the EGFR family members has been reported in a wide range of cancers, and in some studies, has also been associated with poor prog- 
nosis and resistance to therapeutic options. ${ }^{5,7}$ Moreover, the EGFR family of tyrosine kinases has emerged as an important therapeutic target in malignancies, and to date, numerous antibodies, recombinant proteins, peptide mimetics, and small molecules, such as cetuximab, panitumumab, trastuzumab, gefitinib, erlotinib, and lapatinib, have been developed for targeting $E G F R$ family receptors as therapeutic targets for many kinds of solid tumors. ${ }^{4,7}$ Recent reports have suggested that the functions of different EGFR members contribute to OC tumorigenesis. However, the clinicopathological and prognostic value and expression patterns of EGFR family members in OC remain controversial. ${ }^{8-10}$ In addition, the role of $E G F R$ family members in OC and the underlying molecular mechanism responsible for its involvement in tumor development and progression are largely unknown.

The development of microarray and RNA-sequencing technology has revolutionized RNA and DNA research, which has become a crucial component of biology and biomedical research. ${ }^{11,12}$ In the current study, we extended the knowledge base related to OC based on a variety of large databases, with the purpose of determining the expression patterns, genetic alteration, potential functions, and distinct prognostic values of EGFR family members in OC.

\section{Materials and methods}

\section{Ethics statement}

This study was approved by the Academic Committee of the People's Hospital of China Three Gorges University, and conducted according to the principles expressed in the Declaration of Helsinki. All the datasets were retrieved from the databases, so it was confirmed that written informed consent had been obtained from all patients.

\section{ONCOMINE analysis}

The gene expression array datasets of ONCOMINE (www. oncomine.org), which is a publicly accessible, online cancer microarray database helps facilitate research data from genome-wide expression analyses. ONCOMINE was used to analyze the mRNA levels of EGFR family members in OC. ${ }^{13,14}$ In this study, the Student's $t$-test was used to generate $P$-values for comparison between cancer specimens and normal control datasets. The cutoff $P$-value and fold change were defined as 0.05 and 1 , respectively.

\section{Gene Expression Profiling Interactive Analysis (GEPIA) dataset analysis}

GEPIA is an interactive web server for estimating mRNA expression data based on 9,736 tumors and 8,587 normal samples in The Cancer Genome Atlas (TCGA) and GenotypeTissue Expression dataset projects. GEPIA provides key interactive and customizable functions including differential expression analysis, profiling plotting, correlation analysis, patient survival analysis, similar gene detection, and dimensionality reduction analysis. ${ }^{15}$

\section{The Kaplan-Meier plotter analysis}

The prognostic value of the mRNA expression of EGFR family members was evaluated using an online database, Kaplan-Meier Plotter (www.kmplot.com), which contains gene expression data and survival information of 1,816 clinical OC patients. To analyze the overall survival (OS), progression-free survival (PFS), and post-progression survival (PPS) of patients with OC, patient samples were split into two groups by median expression (high vs low expression) and assessed by a Kaplan-Meier survival plot, with a HR with 95\% CI and log-rank $P$-value. ${ }^{16}$

\section{TCGA and CBioPortal analysis}

Gene alteration frequency of EGFR family member mRNA in OC was performed using CBioPortal for Cancer Genomics (http://www.cbioportal.org). The genomic profiles included mutations, putative copy-number alterations from GISTIC, mRNA expression $\mathrm{z}$ scores, and protein expression $\mathrm{z}$ scores. ${ }^{17}$

\section{Functional enrichment and bioinformatics analysis}

GeneMANIA (http://www.genemania.org) is a flexible, userfriendly web interface for generating hypotheses about gene function, analyzing gene lists, and prioritizing genes for functional assays. GeneMANIA was used to conduct correlation analysis of EGFR family members at the gene level, which revealed relationships in pathways, shared protein domains, co-localization, and co-expression. ${ }^{18}$ Finally, enrichment analysis was performed with The Database for Annotation, Visualization and Integrated Discovery (DAVID) (version 6.7) for $E G F R$ family members and their neighboring genes. DAVID includes the gene ontology (GO) terms and Kyoto Encyclopedia of Genes and Genomes (KEGG) pathways. ${ }^{19,20}$

\section{Results \\ Transcription levels of EGFR family members in patients with $O C$}

Using ONCOMINE analysis, four EGFR family members have been identified in human cancers, including hematological malignancies and solid tumors (Figure 1). ONCOMINE analysis revealed that the mRNA expression levels of $E R B B 3$ 

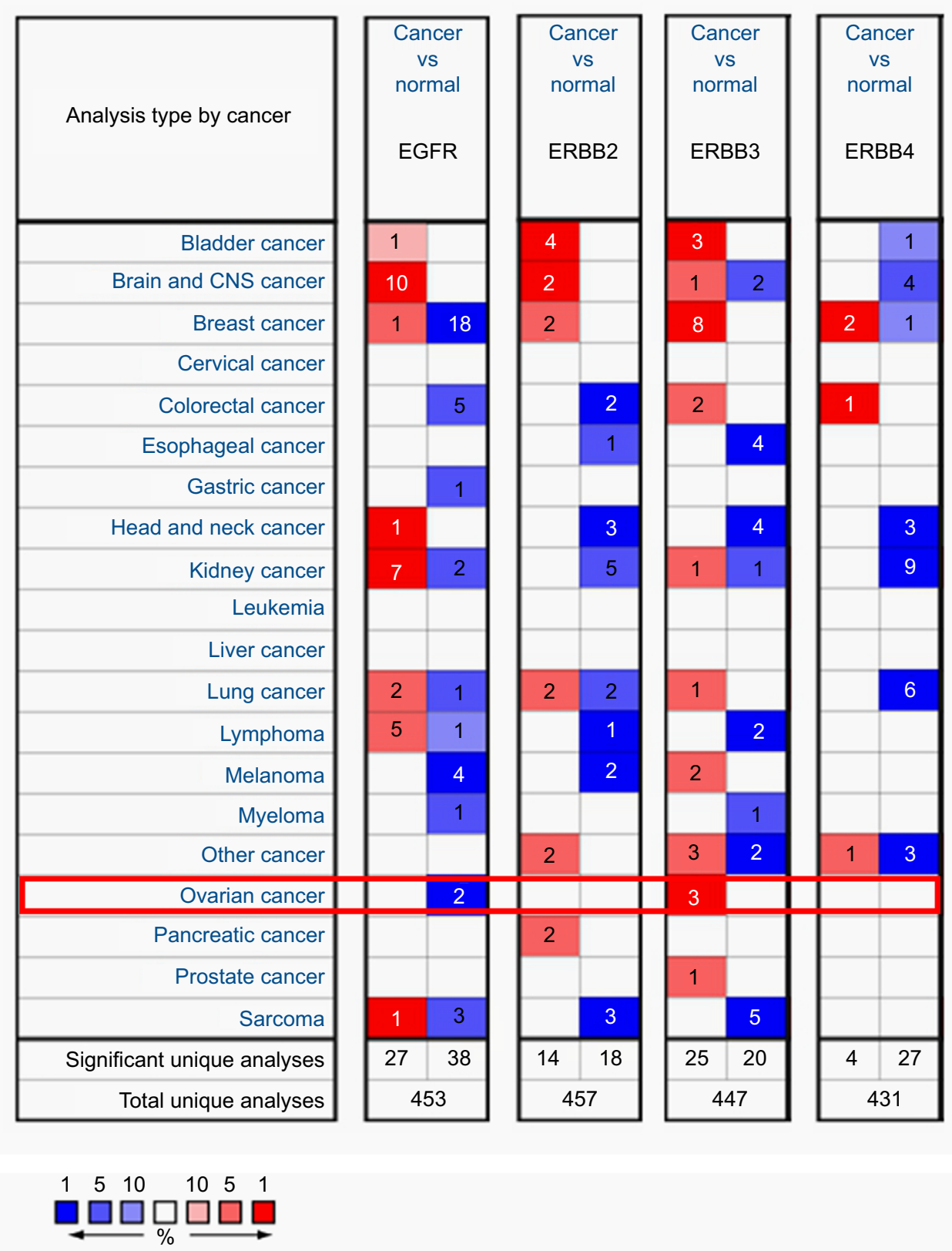

Cell color is determined by the best gene rank percentile for the analyses within the cell

Note: An analysis may be counted in more than one cancer type.

Figure I The transcription levels of EGFR family members in different types of cancers (ONCOMINE).

Notes: The graphic demonstrated the numbers of datasets with statistically significant mRNA over-expression (red) or down-expression (blue) of the target gene. The threshold was designed with following parameters: $P$-value $=0.00 \mathrm{I}$; fold-change $=1.5$ and data type, $\mathrm{mRNA}$.

Abbreviations: EGFR, epidermal growth factor receptor; ERBB2, receptor tyrosine-protein kinase erbB-2; ERBB3, receptor tyrosine-protein kinase erbB-3; ErbB4, receptor tyrosine-protein kinase erbB-4.

were significantly upregulated in patients with $O C$ in three datasets. In Hendrix's dataset, ${ }^{21}$ ERBB3 is overexpressed compared with that in the normal samples in all OC types ovarian mucinous adenocarcinoma with a fold change of 2.355 , ovarian clear cell adenocarcinoma with a fold change of 2.308, ovarian endometrioid adenocarcinoma with a fold change of 1.897 , and ovarian serous adenocarcinoma with a fold change of 1.857. In Adib's dataset, ${ }^{22}$ ERBB3 is overexpressed in ovarian serous adenocarcinoma with a fold change of 1.807. In Lu's dataset, ${ }^{23} E R B B 3$ is overexpressed in ovarian endometrioid adenocarcinoma with a fold change of 1.635 and in ovarian serous adenocarcinoma with a fold change of 1.947 compared with that in the normal samples. The transcription levels of $E G F R$ in ovarian serous adenocarcinoma were 
lower than that in normal ovarian tissues in two datasets (fold changes were -1.223 and -1.349 , respectively) $)^{22,24}$ (Table 1).

As shown in Table 1, the transcription levels of ERBB2 and $E R B B 4$ in different pathological types of OC (eg, ovarian endometrioid adenocarcinoma, ovarian mucinous adenocarcinoma, ovarian serous adenocarcinoma, ovarian clear cell adenocarcinoma, ovarian serous surface papillary carcinoma, ovarian serous adenocarcinoma, and ovarian carcinoma) were also slightly higher than those in normal ovarian tissues, and their cutoff of $P$-value was $>0.05$.

In addition, using the GEPIA dataset (http://gepia.cancerpku.cn/), we compared the mRNA expression of EGFR family members between $\mathrm{OC}$ and normal tissues. The results demonstrated that the mRNA expression levels of $E R B B 3$ and $E R B B 4$ were significantly higher in OC tissues than in normal ovarian tissues, whereas the expression level of $E G F R$ was significantly lower in the former than in the latter. We also analyzed the expression of EGFR family members in different tumor stages of OC. None of the EGFR family members varied in the different tumor stages (Figure 2).

\section{Prognostic values of EGFR family members in all patients with OC}

Using Kaplan-Meier plotter analysis, we initially assessed the prognostic significance of the EGFR family members in all OC patients. The Kaplan-Meier survival curves are demonstrated in Figure 3. The increased EGFR mRNA level and the decreased $E R B B 2$ and $E R B B 3$ mRNA levels were strongly associated with the poor OS. However, high mRNA levels of EGFR or low mRNA levels of ERBB4 were predicted to have high $P F S$. In addition, the mRNA expression levels of $E G F R, E R B B 2, E R B B 3$, and $E R B B 4$ were not correlated with PPS of all patients with OC.

The prognostic value of EGFR family members was assessed in different pathological histology subtypes of OC, including serous and endometrioid. As shown in Table 2, high $E R B B 2$ mRNA expression was correlated to longer OS in serous OC patients. The mRNA expression levels of $E G F R$ and $E R B B 4$ were associated with poor OS in serous OC patients. Increased $E G F R, E R B B 2$, and $E R B B 3$ mRNA expression levels were associated with poor $P F S$. In endometrioid OC, high ERBB4 mRNA expression level was associated with better OS. The rest of the EGFR family members were not related with prognosis in endometrioid OC.

\section{Prognostic values of EGFR family members in OC patients with different clinicopathological features}

To further assess the association of individual EGFR family members with other clinicopathological features, we assessed

Table I The transcription levels of EGFR family members between different types of OC and normal tissues (ONCOMINE)

\begin{tabular}{|c|c|c|c|c|c|c|}
\hline $\begin{array}{l}\text { EGFR family } \\
\text { members }\end{array}$ & Types of OC vs normal & $\begin{array}{l}\text { Fold } \\
\text { change }\end{array}$ & t-Test & $P$-value & Ref & PMID \\
\hline \multirow[t]{2}{*}{ EGFR } & Ovarian serous adenocarcinoma vs normal & -1.223 & -1.44 & 0.906 & Adib Ovarian & 14760385 \\
\hline & Ovarian serous adenocarcinoma vs normal & -1.349 & -2.226 & 0.983 & Yoshihara Ovarian & 19486012 \\
\hline \multirow[t]{8}{*}{ ERBB2 } & Ovarian endometrioid adenocarcinoma vs normal & 1.402 & I I.344 & $2.35 \mathrm{E}-12$ & Hendrix Ovarian & 16452189 \\
\hline & Ovarian mucinous adenocarcinoma vs normal & 1.47 & 9.83 & 3.85E-08 & Hendrix Ovarian & 16452189 \\
\hline & Ovarian serous adenocarcinoma vs normal & 1.408 & 13.145 & $2.76 \mathrm{E}-12$ & Hendrix Ovarian & 16452189 \\
\hline & Ovarian clear cell adenocarcinoma vs normal & 1.826 & 7.306 & 5.99E-05 & Hendrix Ovarian & 16452189 \\
\hline & $\begin{array}{l}\text { Ovarian serous surface papillary carcinoma vs } \\
\text { normal }\end{array}$ & 1.75 & 5.939 & 8.97E-05 & Welsh Ovarian & $111586 \mid 4$ \\
\hline & Ovarian serous adenocarcinoma vs normal & 1.984 & 4.55 & $6.53 E-06$ & Yoshihara Ovarian & 19486012 \\
\hline & Ovarian carcinoma vs normal & 2.484 & 8.219 & 2.85E-06 & Bonome Ovarian & $|859395|$ \\
\hline & Ovarian clear cell adenocarcinoma vs normal & 1.672 & 4.176 & 2.00E-03 & Lu Ovarian & 15161682 \\
\hline \multirow[t]{8}{*}{ ERBB3 } & Ovarian mucinous adenocarcinoma vs normal & 2.355 & 14.003 & 2.04E-09 & Hendrix Ovarian & 16452189 \\
\hline & Ovarian clear cell adenocarcinoma vs normal & 2.308 & 13.845 & 5.07E-08 & Hendrix Ovarian & 16452189 \\
\hline & Ovarian endometrioid adenocarcinoma vs normal & 1.897 & 13.296 & 3.89E-07 & Hendrix Ovarian & 16452189 \\
\hline & Ovarian serous adenocarcinoma vs normal & 1.857 & 13.245 & I.05E-06 & Hendrix Ovarian & 16452189 \\
\hline & Ovarian serous adenocarcinoma vs normal & 1.807 & 5.877 & 6.89E-04 & Adib Ovarian & 14760385 \\
\hline & Ovarian endometrioid adenocarcinoma vs normal & 1.635 & 4.022 & 9.I4E-04 & Lu Ovarian & 15161682 \\
\hline & Ovarian serous adenocarcinoma vs normal & 1.947 & 4.391 & I.07E-04 & Lu Ovarian & 15161682 \\
\hline & Ovarian serous adenocarcinoma vs normal & II.326 & 7.647 & 2.03E-06 & Yoshihara Ovarian & 19486012 \\
\hline \multirow[t]{3}{*}{ ERBB4 } & Ovarian serous adenocarcinoma vs normal & 1.725 & 13.668 & I.67E- 17 & Hendrix Ovarian & 16452189 \\
\hline & Ovarian endometrioid adenocarcinoma vs normal & 1.465 & 9.503 & $5.9 I E-12$ & Hendrix Ovarian & 16452189 \\
\hline & Ovarian clear cell adenocarcinoma vs normal & 1.646 & 4.866 & 8.73E-04 & Hendrix Ovarian & 16452189 \\
\hline
\end{tabular}

Notes: $P$-value was analyzed using the $t$-test. The bold font indicates that the difference was statistically significant between the $O C$ and normal tissue group. Abbreviations: EGFR, epidermal growth factor receptor; ERBB2, receptor tyrosine-protein kinase erbB-2; ERBB3, receptor tyrosine-protein kinase erbB-3; ERBB4, receptor tyrosine-protein kinase erbB-4; OC, ovarian cancer; PMID, PubMed unique identifier; Ref, references. 


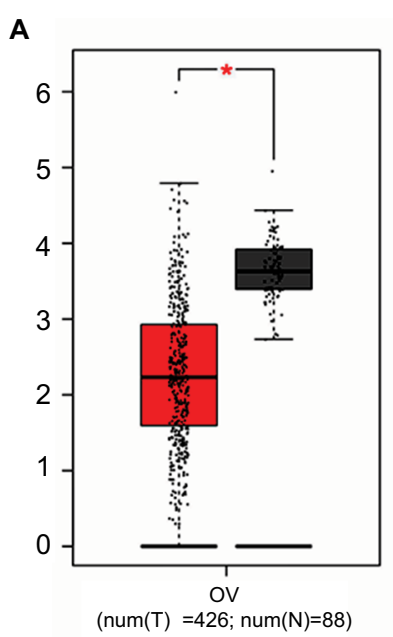

EGFR

E

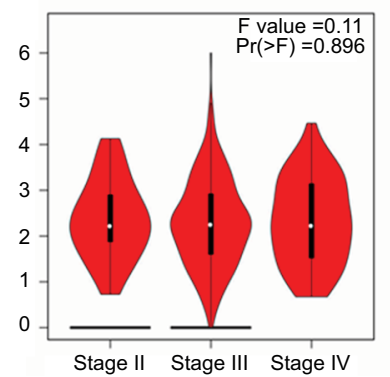

B

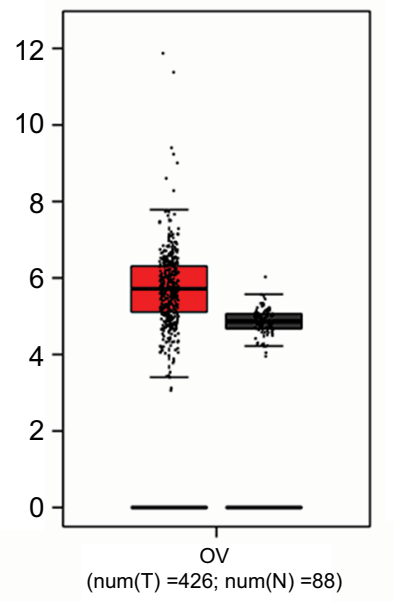

ERBB2

$\mathbf{F}$

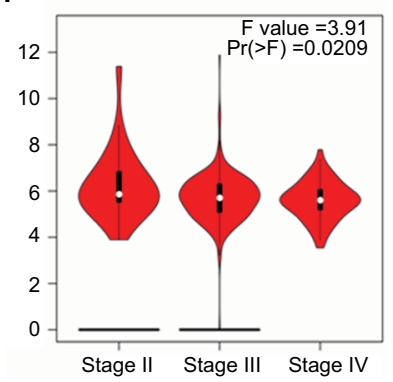

C

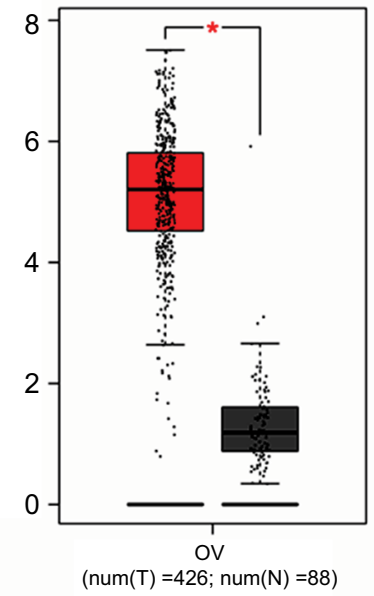

ERBB3

G

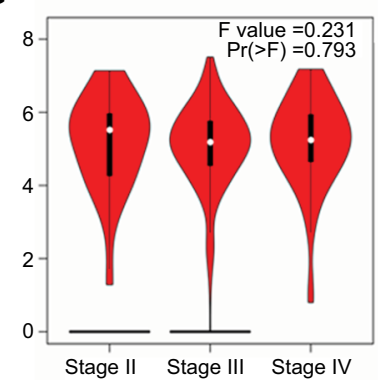

D

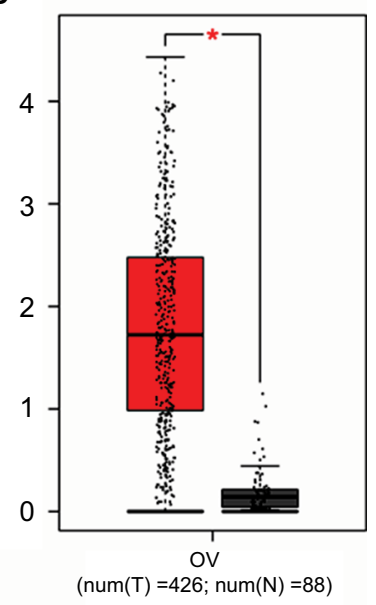

ERBB4

H

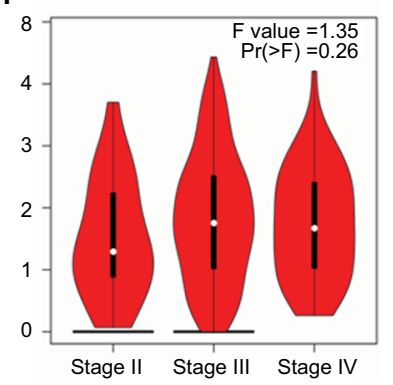

Figure 2 The expression of EGFR family members and tumor stage in OC patients (GEPIA).

Notes: Box plots derived from gene expression data in GEPIA comparing expression of a specific EGFR family member in OC tissue and normal tissues, the $P$-value was set up at 0.05. (A) The distribution of EGFR mRNA expression; (B) the distribution of ERBB2 mRNA expression; (C) the distribution of ERBB3 mRNA expression; (D) the distribution of ERBB3 mRNA expression between OC tissue and normal tissues; (E) correlation between EGFR expression and tumor stage; (F) correlation between ERBB2 expression and tumor stage; $(\mathbf{G})$ correlation between ERBB3 expression and tumor stage; $(\mathbf{H})$ correlation between ERBB4 expression and tumor stage in OC patients. Abbreviations: EGFR, epidermal growth factor receptor; ERBB2, receptor tyrosine-protein kinase erbB-2; ERBB3, receptor tyrosine-protein kinase erbB-3; ERBB4, receptor tyrosine-protein kinase erbB-4; OC, ovarian cancer; $\mathrm{T}$, tumor; N, normal.

the correlation between them with pathological grades, clinical grades, and TP53 status of OC patients (Table 3). As shown in Table 3, high mRNA expression of ERBB4 was associated with better OS and PFS in pathological grade I OC patients. Elevated mRNA expression of ERBB3 was associated with better OS and PFS in grade II OC patients. In pathological grade III OC patients, high EGFR and ERBB4 mRNA expression was linked to poor OS or PFS, but high $E R B B 2$ mRNA expression was found to be correlated to longer OS. None of the EGFR family members were related with prognosis in grade IV OC patients. In terms of clinical staging, as we can see from Table 3, increased mRNA expression of $E R B B 2$ and $E R B B 4$ was associated with longer PFS, but high mRNA expression of $E R B B 2$ was linked to poor OS in clinical stage I and II patients. For clinical stage III and IV OC patients, high mRNA expression of EGFR and ERBB2 was associated with poor PFS in this subgroup. Additionally, Table 3 also shows that high mRNA expression levels of
$E R B B 2$ and $E R B B 3$ were associated with poor OS and PFS, and elevated mRNA expression of EGFR was associated with poor PFS in mutated-TP53-type OC. However, high mRNA expression level of ERBB 4 was associated with better PFS in this subgroup.

\section{Genetic alteration and neighbor genes of EGFR family members in OC}

We analyzed the genetic alterations of $E G F R$ family members by using the cBioPortal online tool for OC. A total of 839 patients from three datasets of ovarian serous cystadenocarcinoma and 12 patients from one dataset of small cell carcinoma were analyzed. Among $4^{\circ} \mathrm{C}$ datasets analyzed, alterations ranging from $10.3 \%(58 / 563)$ to $13.7 \%(83 / 606)$ were found for the gene sets submitted for analysis (Figure 4A). The percentages of genetic alterations in EGFR family members for OC varied from $2.7 \%$ to $5.0 \%$ for individual genes (EGFR, 2.7\%; ERBB2, 4\%; ERBB3, 5\%; and ERBB4, 
A

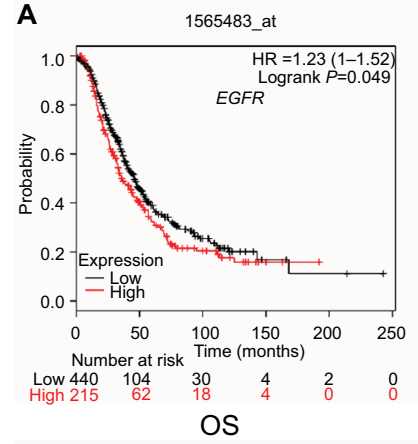

E
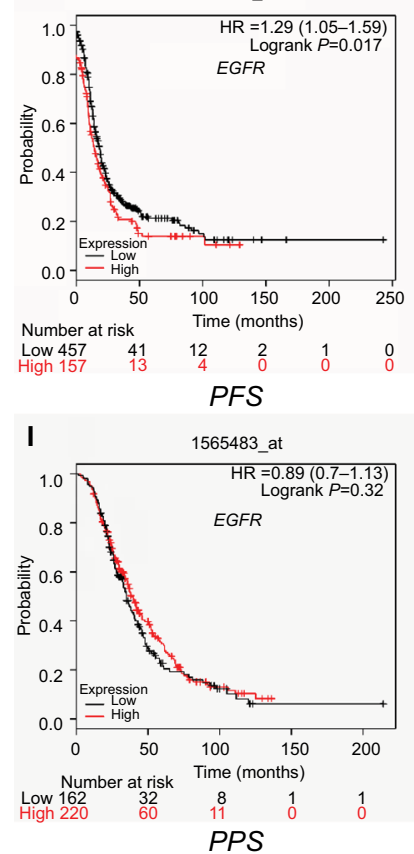

B
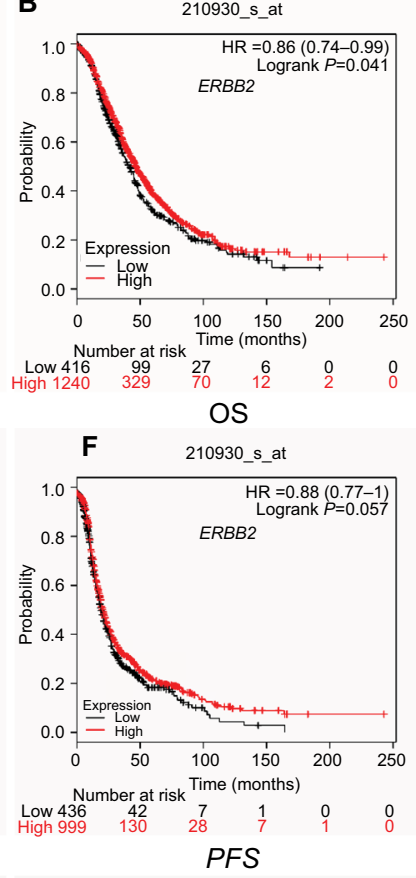

J

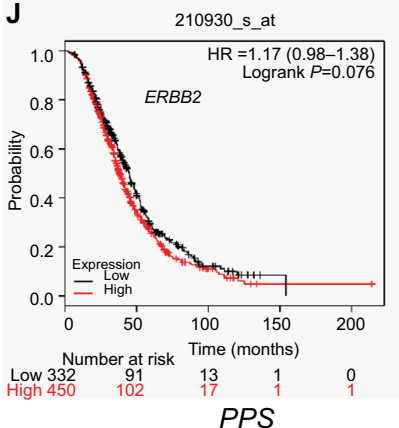

C

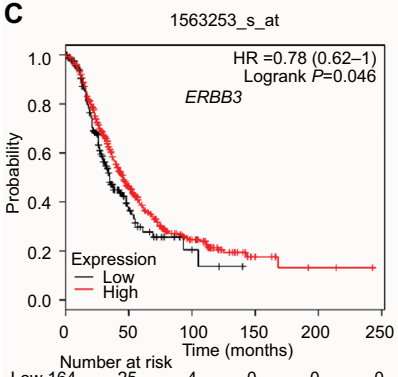

G
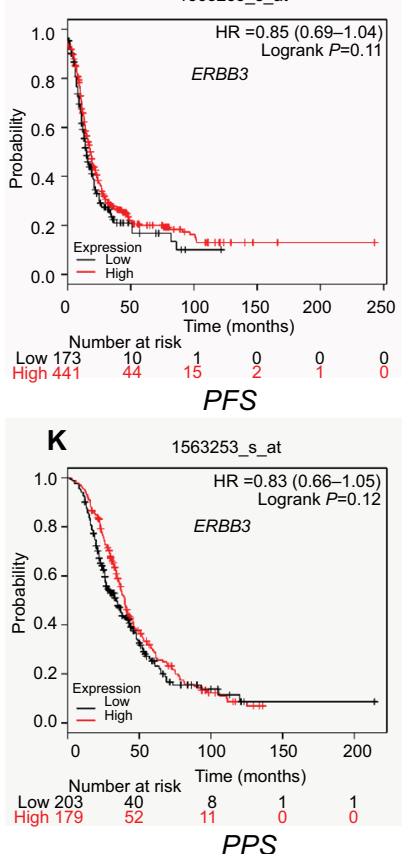

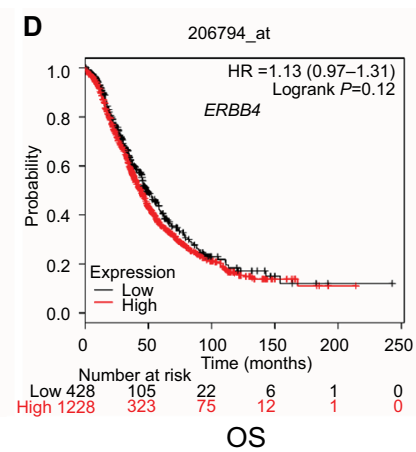

H

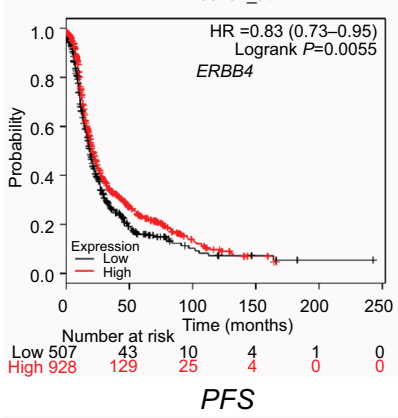

L

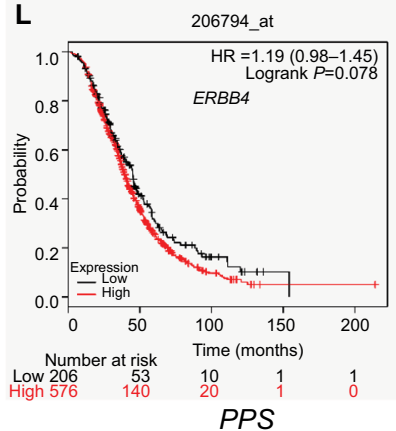

Figure 3 The prognostic value of mRNA level of EGFR family members in OC patients (Kaplan-Meier plotter).

Notes: The OS, PFS, and PPS survival curve comparing the patient with high (red) and low (black) EGFR family members' expression in OC were plotted from Kaplan-Meier plotter database as the threshold of $P$-value $<0.05$, respectively. OS curves of (A) EGFR (Affymetrix IDs: I565483_at); (B) ERBB2 (Affymetrix IDs: 2 I0930_s_at); (C) ERBB3 (Affymetrix IDs: 1563253_s_at); (D) ERBB4 (Affymetrix IDs: 206794_at). PFS curves of (E) EGFR (Affymetrix IDs: I565483_at); (F) ERBB2 (Affymetrix IDs: 210930_s_at); (G) ERBB3 (Affymetrix IDs: 1563253_s_at); (H) ERBB4 (Affymetrix IDs: 206794_at). PPS curves of (I) EGFR (Affymetrix IDs: I565483_at); (J) ERBB2 (Affymetrix IDs: 210930_s_at); (K) ERBB3 (Affymetrix IDs: I563253_s_at); (L) ERBB4 (Affymetrix IDs: 206794_at).

Abbreviations: EGFR, epidermal growth factor receptor; ERBB2, receptor tyrosine-protein kinase erbB-2; ERBB3, receptor tyrosine-protein kinase erbB-3; ERBB4, receptor tyrosine-protein kinase erbB-4; OS, overall survival; PFS, progression-free survival; PPS, post-progression survival.

5\%) (Figure 4B). After cBioPortal, Kaplan-Meier plotter and log-rank test, the results indicated that there are no significant difference in OS and disease-free survival (DFS) in cases with or without alterations in one of the EFGR family genes ( $P$-values, 0.454 and 0.321, respectively) (Figure 4C, D). We then constructed a network for $E G F R$ family members with the structure or function of neighboring genes using GeneMANIA. The results showed that 20 genes $-A B L 1, A B L 2$, $A N K S 1 A, A N K S 1 B, B T C, C R K, E R E G, G R A P 2, G R B 2$, GRB7, NRG1, NRG2, PIK3R2, PIK3R3, PLCG2, PTK6, SHC1, SHC4, TGFA, and TNS3 - were closely associated with EGFR family members (Figure 4E). GeneMANIA also was used to conduct correlation analysis of $E G F R$ family members at the gene level. There were relationships between $E G F R$ and $E R B B 2$ in co-expression, pathway, physical interactions, and shred protein domains. There were also relationships between $E G F R$ and $E R B B 3$ in pathway, physical interactions, and shred protein domains. There were physical interactions, prediction, and shared protein domains between $E G F R$ and $E R B B 4$. In addition, there were relationships in co-expression, co-localization, pathway, physical interactions, shared protein domains, and prediction between $E R B B 2$ and $E R B B 3$. There were relationships between EEBB2 and $E R B B 4$ in pathway, physical interactions, prediction, and 
Table 2 The prognostic values of EGFR family members in all and different pathological subtypes OC patients (Kaplan-Meier plotter)

\begin{tabular}{|c|c|c|c|c|c|c|c|c|c|}
\hline \multirow[t]{2}{*}{ EGFR family } & \multirow[t]{2}{*}{ Histology } & \multicolumn{4}{|l|}{ os } & \multicolumn{4}{|l|}{ PFS } \\
\hline & & Cases & HR & $95 \% \mathrm{Cl}$ & $P$-value & Cases & HR & $95 \% \mathrm{Cl}$ & $P$-value \\
\hline EGFR & Overall & 655 & 1.23 & $1.00-1.52$ & 0.049 & 617 & 1.29 & I.05-I.59 & 0.017 \\
\hline \multirow[t]{2}{*}{ 1565483_at } & Serous & 523 & 1.31 & $1.03-1.66$ & 0.027 & $\mathrm{I}, 104$ & 1.33 & $1.06-1.67$ & 0.013 \\
\hline & Endometrioid & 30 & - & - & 0.260 & 44 & 2.01 & $0.45-8.97$ & 0.350 \\
\hline ERBB2 & Overall & 1,656 & 0.86 & $0.74-0.99$ & $0.04 I$ & 1,435 & 0.88 & $0.70-1.00$ & 0.057 \\
\hline \multirow[t]{2}{*}{ 210930_s_at } & Serous & 1,207 & 0.80 & $0.68-0.95$ & 0.009 & 1,104 & 1.25 & $1.08-1.45$ & 0.002 \\
\hline & Endometrioid & 37 & 0.29 & $0.03-2.56$ & 0.230 & 51 & 0.53 & $0.19-1.49$ & 0.230 \\
\hline ERBB3 & Overall & 655 & 0.78 & $0.62-1.00$ & 0.046 & 614 & 0.85 & $0.69-1.04$ & 0.110 \\
\hline \multirow[t]{2}{*}{ 1563253_s_at } & Serous & 523 & 1.22 & $0.97-1.53$ & 0.084 & 483 & 1.26 & $1.01-1.56$ & 0.004 \\
\hline & Endometrioid & 30 & - & - & 0.020 & 44 & 2.66 & $0.44-9.57$ & 0.120 \\
\hline ERBB4 & Overall & 1,656 & 1.13 & $0.97-1.31$ & 0.120 & 1,435 & 0.83 & $0.73-0.95$ & 0.006 \\
\hline \multirow[t]{2}{*}{ 206794_at } & Serous & $\mathrm{I}, 207$ & 1.27 & $|.07-| .5 \mid$ & 0.006 & $\mathrm{I}, 104$ & 0.88 & $0.75-1.03$ & 0.110 \\
\hline & Endometrioid & 37 & 0.14 & $0.02-0.24$ & 0.039 & 51 & 0.53 & $0.21-1.34$ & 0.170 \\
\hline
\end{tabular}

Notes: $P$-value was analyzed using the survival analysis test. The bold font indicates that the difference was statistically significant.

Abbreviations: EGFR, epidermal growth factor receptor; ERBB2, receptor tyrosine-protein kinase erbB-2; ERBB3, receptor tyrosine-protein kinase erbB-3; ERBB4, receptor tyrosine-protein kinase erbB-4; OC, ovarian cancer; OS, overall survival; PFS, progression-free survival.

shred protein domains. ERBB3 and ERBB4 shared physical interactions, prediction, and shred protein domains. Detailed results are presented in Figure 4E.

\section{Significant functions and pathway enrichment analysis of EGFR family members in OC}

The functions of EGFR family members and their neighboring genes were predicted by analyzing GO and KEGG in DAVID. Based on DAVID, a total of 58 GO functions were enriched. The enrichment items were classified into three functional groups: biological process (BP) group (10 items), molecular function (MF) group (41 items), and cellular component (CC) group (7 items). As shown in Table 4, the EGFR family members and their neighboring genes were mainly enriched in the following BP: transmembrane receptor protein tyrosine kinase signaling pathway, EGFR signaling pathway, insulin receptor signaling pathway, positive regulation of cell proliferation, and cell differentiation. The MF that these genes were mainly associated with are receptor binding, non-membrane spanning protein tyrosine kinase activity, manganese ion binding, ATP binding, and receptor tyrosine kinase binding; the $\mathrm{CC}$ that these genes were associated with are the extrinsic component of the cytoplasmic side of the plasma membrane, extracellular space, and phosphatidylinositol 3-kinase complex, and the focal adhesion and receptor complex.

Next, 51 pathways related to the functions of EGFR family members were found through KEGG analysis. The top ten KEGG pathways for EGFR family members are shown in Figure 5. Among these pathways, the ErbB signaling pathway, neurotrophin signaling pathway, Ras signaling pathway,
microRNAs in cancer, proteoglycans in cancer, and focal adhesion were found to be involved in OC tumorigenesis and pathogenesis.

\section{Discussion}

Accumulative studies have determined that aberrant expression or activation of the EGFR family members is a common feature in human cancers, and the functions of different $E G F R$ family members are associated with tumorigenesis and progression of solid tumors. ${ }^{4,5,7,25-27}$ However, the patterns of expression and the exact roles the distinct EGFR family members play in contributing to $\mathrm{OC}$ are yet to be elucidated..$^{8-10,28}$ In the current study, we comprehensively explored the expression patterns, prognostic values (OS, PFS, and PPS), genetic alteration, and potential functions of different $E G F R$ family members based on a variety of large databases.

Among the EGFR family members, EGFR is the most studied in OC since it was first identified in the 1970s. ${ }^{29}$ Till date, various cancer cells are characterized by EGFR hyperactivation, overexpression, or mutants with dysregulated signaling. EGFR and its signaling activity have been targets for developing novel therapeutic drugs to treat a variety of cancers. ${ }^{30-33}$ Recent studies confirmed that amplification and overexpression of $E G F R$ have been reported in several solid cancers, and a growing body of research interests has focused on the prognostic value and therapeutic potential of $E G F R$ for OC. ${ }^{8-10,28}$ In our study, ONCOMINE and GEPIA datasets revealed that the mRNA expression of EGFR was lower in OC than in normal tissues. This inconsistent expression pattern might be because ONCOMINE and GEPIA only represent mRNA data, which only correlate to $\sim 40 \%$ of the total protein 
Table 3 The prognostic values of EGFR family members in OC patients with different clinicopathological features (Kaplan-Meier plotter)

\begin{tabular}{|c|c|c|c|c|c|c|c|c|c|}
\hline \multirow[t]{2}{*}{ EGFR family } & \multirow{2}{*}{$\begin{array}{l}\text { Clinicopathological } \\
\text { features }\end{array}$} & \multicolumn{4}{|l|}{ OS } & \multicolumn{4}{|l|}{ PFS } \\
\hline & & Cases & HR & $95 \% \mathrm{Cl}$ & $P$-value & Cases & HR & $95 \% \mathrm{Cl}$ & $P$-value \\
\hline \multicolumn{10}{|c|}{ Pathological grade } \\
\hline EGFR & 1 & 41 & 2.71 & $0.60-12.35$ & 0.180 & 28 & 3.44 & $0.43-27.54$ & 0.220 \\
\hline \multirow[t]{3}{*}{ 1565483_at } & II & 162 & 0.78 & $0.50-1.20$ & 0.250 & 161 & 0.78 & $0.54-1.33$ & 0.190 \\
\hline & III & 392 & 1.38 & $1.07-1.78$ & 0.013 & 315 & 1.37 & $1.04-1.81$ & 0.026 \\
\hline & IV & 18 & - & - & - & 18 & - & - & - \\
\hline ERBB2 & 1 & 56 & 0.55 & $0.19-1.57$ & 0.250 & 37 & 0.47 & $0.15-1.45$ & 0.180 \\
\hline \multirow[t]{3}{*}{ 210930_s_at } & ॥ & 324 & 1.27 & $0.94-1.72$ & 0.120 & 256 & 1.39 & $0.99-1.95$ & 0.058 \\
\hline & III & 1,015 & 0.79 & $0.66-0.95$ & 0.014 & 837 & 1.18 & $1.00-1.40$ & 0.520 \\
\hline & IV & 20 & 0.6 & $0.20-1.75$ & 0.340 & 19 & - & - & - \\
\hline ERBB3 & 1 & 41 & 0.43 & $0.14-1.34$ & 0.130 & 28 & 2.79 & $0.35-22.33$ & 0.310 \\
\hline \multirow[t]{3}{*}{ 1563253_s_at } & ॥ & 162 & 0.52 & $0.32-0.85$ & 0.008 & 161 & 0.49 & $0.33-0.71$ & 0.000 \\
\hline & III & 392 & 0.8 & $0.59-1.06$ & 0.120 & 315 & 1.19 & $0.92-1.53$ & 0.180 \\
\hline & IV & 18 & - & - & - & 18 & - & - & - \\
\hline ERBB4 & I & 56 & 0.24 & $0.09-0.65$ & 0.003 & 37 & 0.33 & $0.11-1.01$ & 0.041 \\
\hline \multirow[t]{3}{*}{ 206794_at } & II & 324 & 1.38 & $0.96-1.98$ & 0.078 & 256 & 1.15 & $0.82-1.62$ & 0.420 \\
\hline & III & 1,015 & 1.26 & $1.04-1.52$ & 0.018 & 837 & 0.86 & $0.7 \mid-1.03$ & 0.100 \\
\hline & IV & 20 & 0.42 & $0.15-1.15$ & 0.081 & 19 & - & - & - \\
\hline \multicolumn{10}{|l|}{ Clinical stage } \\
\hline EGFR & $\mathrm{I}+\mathrm{II}$ & 83 & 2.7 & $0.6 \mathrm{I}-\mathrm{II} .98$ & 0.170 & 115 & 0.50 & $0.23-1.10$ & 0.080 \\
\hline 1565483_at & III + IV & 487 & 0.87 & $0.69-1.09$ & 0.230 & 494 & 1.30 & $1.05-1.6 \mathrm{I}$ & 0.016 \\
\hline ERBB2 & I+II & 135 & 2.86 & $0.98-8.33$ & 0.043 & 163 & 0.52 & $0.27-0.99$ & 0.042 \\
\hline 210930_s_at & III + IV & 1,220 & 0.88 & $0.75-1.03$ & 0.099 & $|, 08|$ & 1.25 & $1.07-1.46$ & 0.005 \\
\hline ERBB3 & I+II & 83 & 0.54 & $0.19-1.54$ & 0.240 & 115 & 0.53 & $0.25-1.14$ & 0.099 \\
\hline 1563253_s_at & $\mathrm{III}+\mathrm{IV}$ & 487 & 1.15 & $0.91-1.45$ & 0.230 & 494 & 1.12 & $0.91-1.38$ & 0.260 \\
\hline ERBB4 & I+II & 135 & 0.53 & $0.24-1.16$ & 0.110 & 163 & 0.48 & $0.26-0.89$ & 0.017 \\
\hline 206794_at & III + IV & 1,220 & 0.86 & $0.74-1.01$ & 0.062 & $|, 08|$ & 0.83 & $0.7 \mathrm{I}-0.97$ & 0.018 \\
\hline \multicolumn{10}{|c|}{ TP53 mutation } \\
\hline EGFR & mutated & 124 & 1.33 & $0.91-1.95$ & 0.130 & 124 & 1.59 & $\mid .09-2.3 \mathrm{I}$ & 0.001 \\
\hline 1565483_at & wild type & 19 & - & - & - & 19 & - & - & - \\
\hline ERBB2 & mutated & 506 & 1.52 & $1.21-1.91$ & 0.000 & 483 & 1.55 & $1.24-1.95$ & 0.000 \\
\hline 210930_s_at & wild type & 94 & 1.61 & $0.92-2.81$ & 0.095 & 84 & 0.68 & $0.38-1.19$ & 0.170 \\
\hline ERBB3 & mutated & 124 & 1.63 & $1.07-2.50$ & 0.023 & 124 & 1.76 & $1.17-2.66$ & 0.006 \\
\hline 1563253_s_at & wild type & 19 & - & - & - & 19 & - & - & - \\
\hline ERBB4 & mutated & 506 & 1.16 & $0.90-1.49$ & 0.240 & 483 & 0.78 & $0.6 \mathrm{I}-1.00$ & 0.047 \\
\hline 206794_at & wild type & 94 & 1.32 & $0.73-2.37$ & 0.360 & 84 & 0.70 & $0.42-1.18$ & 0.180 \\
\hline
\end{tabular}

Notes: $P$-value was analyzed using the survival analysis test. The bold font indicates that the difference was statistically significant.

Abbreviations: EGFR, epidermal growth factor receptor; PFS, progression-free survival; ERBB3, receptor tyrosine-protein kinase erbB-3; ERBB2, receptor tyrosine-protein kinase erbB-2; ERBB4, receptor tyrosine-protein kinase erbB-4; OC, ovarian cancer; OS, overall survival.

levels. ${ }^{34}$ Consistent with the results of most previous studies, our results demonstrated that EGFR expression was not correlated with the clinical stage of the patients with $\mathrm{OC}$, and an increased $E G F R$ expression was significantly associated with poor OS and PPS in the patients with OC, especially in serous and advanced OC. However, several different studies suggest that $E G F R$ is not a reliable marker of survival in OC. ${ }^{29,35,36}$ The utility of EGFR expression as an independent prognostic indicator in OC patients is yet to be confirmed. ${ }^{37,38}$

$E R B B 2$ is a tyrosine kinase receptor in the EGFR family and plays a pivotal role in cell proliferation and tumor cell metastasis. ${ }^{39,40}$ Previous studies have demonstrated that
$E R B B 2$ overexpression or mutations in human malignant cancers correlate with poor prognosis and chemo-resistance. ${ }^{40-42}$ Until now, the association between $E R B B 2$ expression and OC has been widely studied, however, its relationship with disease stage, grade, and response to treatment remains controversial. ${ }^{43-45} \mathrm{~A}$ recent meta-analysis study showed that HER2 expression can be used as a prognostic biomarker in OC patients. ${ }^{46}$ Our results demonstrated that the transcription levels of ERBB2 in different pathological types of OC were not remarkably higher than those in normal tissues, and increased $E R B B 2$ mRNA levels were significantly associated with the better OS, especially in clinical stage I and II 
A

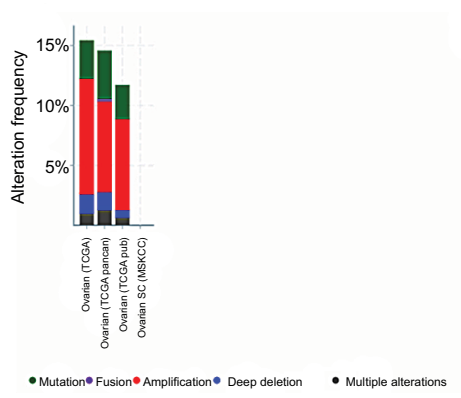

B

Altered in $143(14 \%)$ of 1,036 sequenced cases/patients (1,036 total)

Study of origin : $\quad$ ||||||||||||||||||||||||||||||||||||||||||||||||||||||||||||||||||||||||||||||||||||||||||||||||||||||||||||||||||||||||||||||||||||||||||||||||||||

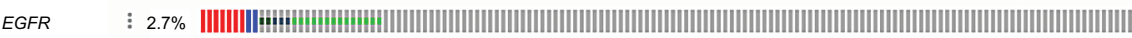

ERBB2 $\quad \vdots 4 \% \quad$ -

ERBB3 $\quad: 5 \% \quad$ |

ERBB4 $\quad \vdots 5 \% \quad$ -

Genetic alteration

II Fusion | Amplification | Deep deletion $\|$ No alteration

| Ovarian serous cystadenocarcinoma (TCGA, nature 2011) I Ovarian serous cystadenocarcinoma (TCGA, pancancer atlas)

I Ovarian serous cystadenocarcinoma (TCGA, provisional) \Small cell carcinoma of the ovary (MSKCC, Nat genet 2014)

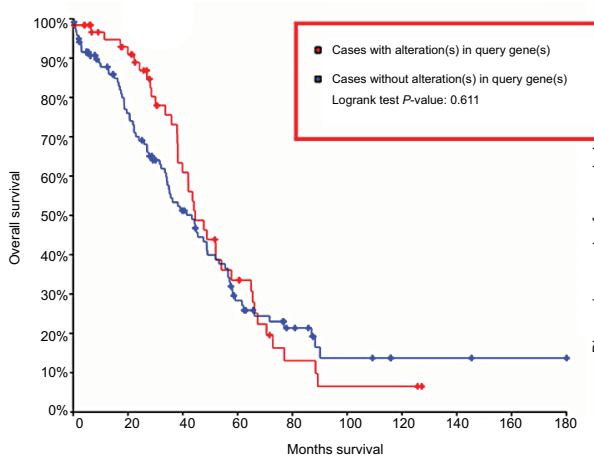

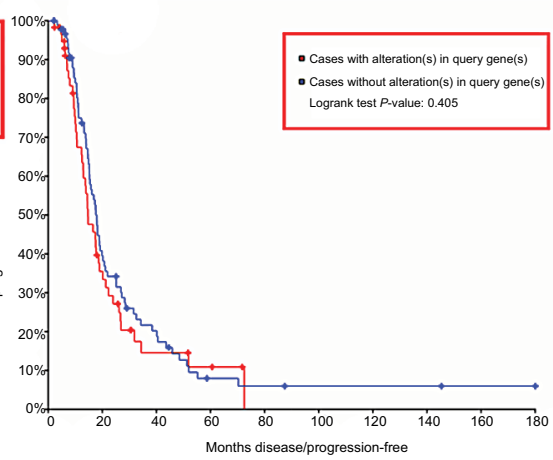

E

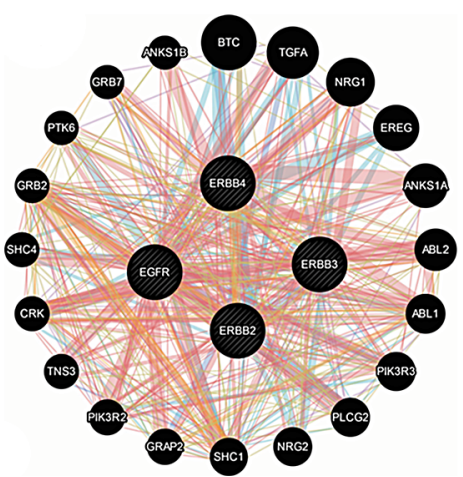

Figure 4 Alteration frequency of EGFR familymembers and neighbor genes network in OC (cBioPortal and GeneMANIA).

Notes: (A) Summary of alteration in EGFR family members. (B) OncoPrint visual summary of alteration on a query of EGFR family members. (C) Kaplan-Meier plots comparing OS in cases with/without EGFR family members gene alterations. (D) Kaplan-Meier plots comparing disease-free survival (DFS) in cases with/without EGFR family member alterations. (E) Gene-gene interaction network among EGFR family members.

Abbreviations: EGFR, epidermal growth factor receptor; ERBB2, receptor tyrosine-protein kinase erbB-2; ERBB3, receptor tyrosine-protein kinase erbB-3; ERBB4, receptor tyrosine-protein kinase erbB-4; OS, overall survival.

OC patients. Interestingly, high expression of $E R B B 2$ was associated with poor PFS in clinical stage III and IV OC patients and with poor OS and PFS in mutated-TP53-type OC patients.

The third member of the EGFR family, $E R B B 3$, unlike the other EGFR family members that are activated through autophosphorylation upon binding with the ligand, lacks an intracellular tyrosine kinase domain. ${ }^{47}$ Therefore, ERBB3 must act as an allosteric activator. It forms heterodimers with other EGFR family members, thus stimulating downstream growth and signaling pathways. ${ }^{48} E R B B 3$ has been shown to be overexpressed in several human carcinomas, and somatic mutations have been found scattered throughout the $E R B B 3$ gene in subsets of breast cancers, gastric cancers, and OC. ${ }^{49-51}$ In addition, $E R B B 3$ has been recently characterized as having a significant role in mediating resistance to EGFR- and $E R B B 2$-directed therapies in solid malignancies, suggesting that $E R B B 3$ also has a role in mediating resistance to PI3K/AKT pathway inhibitors. ${ }^{48,52,53}$ Our study showed that the mRNA expression levels of ERBB3 were considerably upregulated in patients with $\mathrm{OC}$ in three datasets, and increased $E R B B 3$ mRNA levels were associated with the better OS, especially in pathological grade II OC patients. High expression of $E R B B 2$ was associated with poor PFS in serous OC patients and poor OS and PFS in mutated-TP53type OC patients.

$E R B B 4$ is one of the four members in the EGFR subfamily of receptor tyrosine kinases. Unlike $E R B B 2$, which cannot directly bind a ligand, and $E R B B 3$, which does not have a functional kinase domain, $E R B B 4$ is a fully functional receptor tyrosine kinase capable of signaling, both as a homodimer and as a heterodimer. ${ }^{54}$ Among different EGFR family members, the role of ERBB4 in cancer is probably the least understood. ${ }^{55} E R B B 4$ is necessary for the development of the heart, mammary gland, and the central nervous system, and mutations in $E R B B 4$ have been identified in various cancer types including melanoma, lung adenocarcinoma, and medulloblastoma. These results suggest that $E R B B 4$ can be a potential biomarker for malignant tumors. ${ }^{54,56}$ Our results showed that increased expression of $E R B B 4$ might indicate better PFS in all OC patients and longer OS in endometrioid OC patients; however, increased 
Table 4 The GO function enrichment analysis of EGFR family members and neighbor genes in OC (DAVID)

\begin{tabular}{|c|c|c|c|c|}
\hline Category & Term & Description & Count & $P$-value \\
\hline GOTERM_BP_DIRECT & GO:0007I69 & $\begin{array}{l}\text { Transmembrane receptor protein tyrosine kinase } \\
\text { signaling pathway }\end{array}$ & 6 & 4.85E-08 \\
\hline GOTERM_BP_DIRECT & GO:0007I73 & EGFR signaling pathway & 5 & $2.78 \mathrm{E}-07$ \\
\hline GOTERM_BP_DIRECT & GO:0008286 & Insulin receptor signaling pathway & 4 & $3.15 E-05$ \\
\hline GOTERM_BP_DIRECT & GO:0008284 & Positive regulation of cell proliferation & 6 & 4.02E-05 \\
\hline GOTERM_BP_DIRECT & GO:0030I54 & Cell differentiation & 4 & $1.16 \mathrm{E}-03$ \\
\hline GOTERM_MF_DIRECT & GO:00047I6 & Receptor signaling protein tyrosine kinase activity & 4 & 7.99E-08 \\
\hline GOTERM_MF_DIRECT & GO:0005I54 & EGFR binding & 3 & 3.87E-05 \\
\hline GOTERM_MF_DIRECT & GO:00047I4 & Transmembrane receptor protein tyrosine kinase activity & 3 & 2.49E-04 \\
\hline GOTERM_MF_DIRECT & GO:0008083 & Growth factor activity & 3 & $3.46 \mathrm{E}-04$ \\
\hline GOTERM_MF_DIRECT & GO:0046935 & I-Phosphatidylinositol-3-kinase regulator activity & 2 & $5.60 \mathrm{E}-03$ \\
\hline GOTERM_CC_DIRECT & GO:00I6323 & Basolateral plasma membrane & 3 & $3.56 \mathrm{E}-03$ \\
\hline GOTERM_CC_DIRECT & GO:0043235 & Receptor complex & 3 & $3.69 \mathrm{E}-03$ \\
\hline GOTERM_CC_DIRECT & GO:0005925 & Focal adhesion & 4 & I.34E-02 \\
\hline GOTERM_CC_DIRECT & GO:0005942 & Phosphatidylinositol 3-kinase complex & 2 & 2.19E-02 \\
\hline GOTERM_CC_DIRECT & GO:00056I5 & Extracellular space & 5 & 3.03E-02 \\
\hline
\end{tabular}

Notes: The bold font indicates that the difference was statistically significant.

Abbreviations: GO, gene ontology; BP, biological process; CC, cellular component; DAVID, Database for Annotation, Visualization and Integrated Discovery; MF, molecular function.

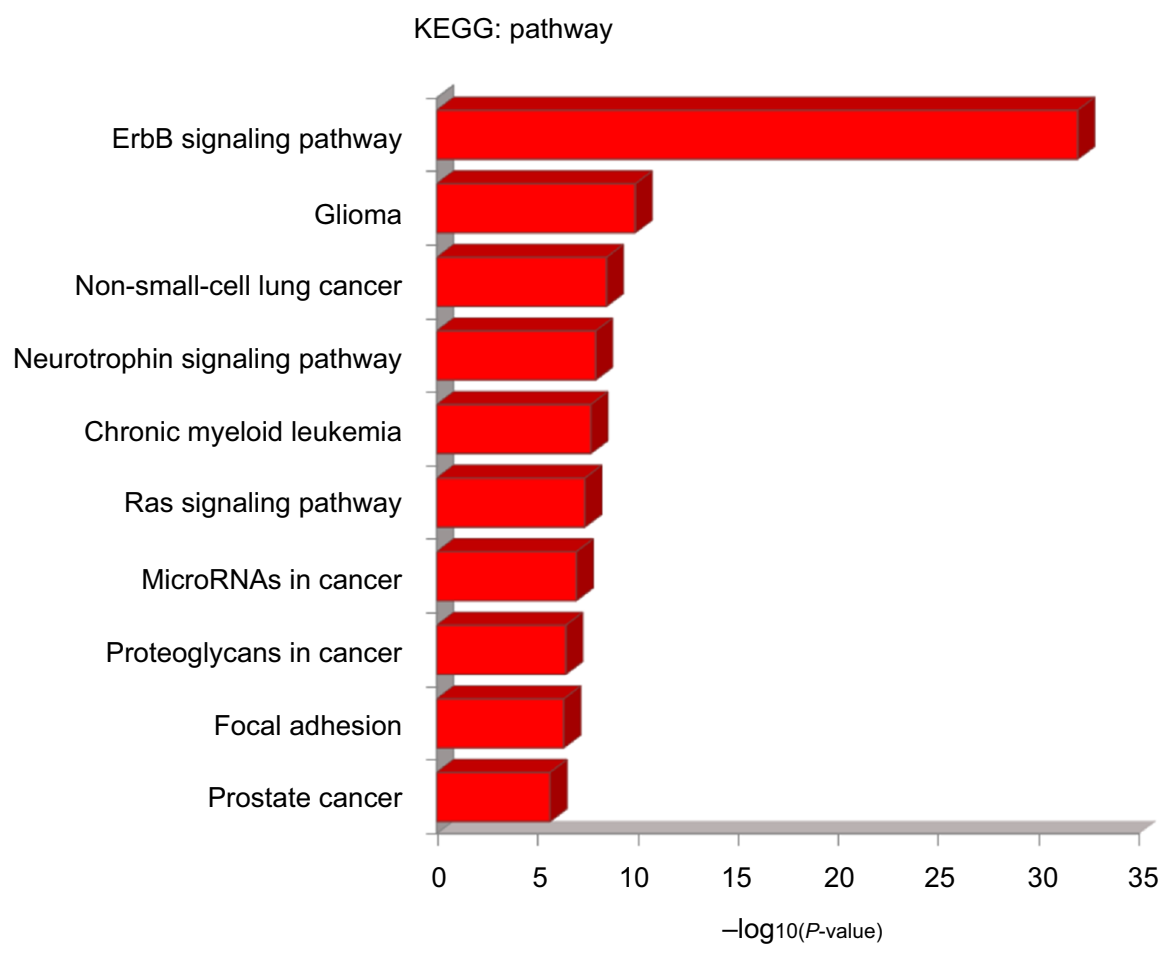

Figure 5 The KEGG pathway enrichment analysis of EGFR family members and neighbor genes in OC (DAVID).

Notes: The graphic demonstrated the functions of EGFR family and genes significantly associated with EGFR family alterations were predicted by analysis of the KEGG. The length of the $\mathrm{X}$-axis represents -log ( $P$-value).

Abbreviations: OC, ovarian cancer; EGFR, epidermal growth factor receptor; KEGG, Kyoto Encyclopedia of Genes and Genomes.

$E R B B 4$ expression may correlate with worse OS in serous OC patients.

Mutations, gene amplification, and protein overexpression of EGFR family members are all linked to carcinogenesis. ${ }^{47}$ Mutant $E G F R$ family members cause a gain-of-function phenotype and are involved in tumorigenesis, invasion, and metastasis. ${ }^{57}$ In our current analysis, we found that the percentages of alterations in EGFR family members among OC varied from $2.7 \%$ to $5.0 \%$ for individual genes, but there is no significant difference in OS and DFS in cases with or without alterations in one of the EFGR family genes ( $P$-values, 0.454 and 0.321 , respectively). To further clarify the carcinogenic 
mechanism of the EGFR family members, we constructed a network for EGFR family members and 20 neighboring genes. The results of GO and KEGG analysis indicated that these genes are mainly enriched in tumor-related pathways, including the ErbB signaling pathway, neurotrophin signaling pathway, and Rams signaling pathway, and in microRNAs and proteoglycans in cancer, and during focal adhesion. Our study adds to the growing evidence regarding the complexity of the EGFR family members and their associated signaling pathways, which offer clues into the rational development of dual targeting with anti-EGFR or HER2 and downstream pathway inhibitors.

To the best of our knowledge, this is the first bioinformatics analysis exploring the distinct expression and prognostic value of EGFR family members in OC. There were some limitations to this study that need to be addressed. First, this is an in silico and bioinformatics analysis based on functional genomics using data from several large databases, which may introduce background heterogeneity. To address these issues, we are planning functional verification studies in well designed in vitro and in vivo models in the near future. In addition, the sample size of the study cohort was limited, and a small fraction of the clinical data was missing. As such, larger studies are needed to clarify these findings. Finally, no multivariable analyses were included; therefore, it is impossible to identify any potential association with other important prognostic factors, such as the FIGO stage, patient age, residual tumor after initial surgery, lymph node metastasis, vascular invasion, cancer antigen 125 , and Human epididymis protein 4, BRCA, Risk of Malignancy Index II, and Risk of Malignancy Algorithm. Therefore, future research is still needed to address these issues.

\section{Conclusion}

In summary, the mRNA expression levels of $E R B B 2 / 3 / 4$ were significantly upregulated, whereas the transcription levels of EGFR were low in patients with OC. Aberrant EGFR expression and $E R B B 2 / 3 / 4 \mathrm{mRNA}$ levels were all found to be associated with the prognosis of OC. These results suggest that $E G F R$ and $E R B B 3 / 4$ may be prognostic biomarkers and potential targets for OC. These results may help us better understand the molecular foundations of OC. They may also be useful for the development of tools that can be used for OC prognosis and may help promote the development of $E G F R$-targeted inhibitors for the treatment of OC.

\section{Disclosure}

This study is funded by the Yichang Medical and Health Research Project (No. A17-301-12) to Quan Zhou. The authors report no other conflicts of interest in this work.

\section{References}

1. Torre LA, Bray F, Siegel RL, Ferlay J, Lortet-Tieulent J, Jemal A. Global cancer statistics, 2012. CA Cancer J Clin. 2015;65(2):87-108.

2. Torre LA, Trabert B, Desantis CE, et al. Ovarian cancer statistics, 2018. CA Cancer J Clin. 2018;68(4):284-296.

3. Holschneider CH, Berek JS. Ovarian cancer: epidemiology, biology, and prognostic factors. Semin Surg Oncol. 2000;19(1):3-10.

4. Roskoski R. The ErbB/HER family of protein-tyrosine kinases and cancer. Pharmacol Res. 2014;79:34-74.

5. Appert-Collin A, Hubert P, Crémel G, Bennasroune A. Role of ErbB Receptors in cancer cell migration and invasion. Front Pharmacol. 2015;6:283.

6. Hyman DM, Piha-Paul SA, Won H, et al. HER kinase inhibition in patients with HER2- and HER3-mutant cancers. Nature. 2018;554(7691): $189-194$.

7. Hynes NE, MacDonald G. ErbB receptors and signaling pathways in cancer. Curr Opin Cell Biol. 2009;21(2):177-184.

8. Sheng Q, Liu J. The therapeutic potential of targeting the EGFR family in epithelial ovarian cancer. Br J Cancer. 2011;104(8): 1241-1245.

9. Wilken JA, Badri T, Cross S, et al. EGFR/HER-targeted therapeutics in ovarian cancer. Future Med Chem. 2012;4(4):447-469.

10. Gui T, Shen K. The epidermal growth factor receptor as a therapeutic target in epithelial ovarian cancer. Cancer Epidemiol. 2012;36(5): 490-496.

11. Sealfon SC, Chu TT. RNA and DNA microarrays. Methods Mol Biol. 2011;671:3-34.

12. Raghavachari N, Barb J, Yang Y, et al. A systematic comparison and evaluation of high density exon arrays and RNA-seq technology used to unravel the peripheral blood transcriptome of sickle cell disease. $B M C$ Med Genomics. 2012;5:28.

13. Rhodes DR, Yu J, Shanker K, et al. ONCOMINE: a cancer microarray database and integrated data-mining platform. Neoplasia. 2004;6(1):1-6.

14. Rhodes DR, Kalyana-Sundaram S, Mahavisno V, et al. Oncomine 3.0: genes, pathways, and networks in a collection of 18,000 cancer gene expression profiles. Neoplasia. 2007;9(2):166-180.

15. Tang Z, Li C, Kang B, Gao G, Li C, Zhang Z. GEPIA: a web server for cancer and normal gene expression profiling and interactive analyses. Nucleic Acids Res. 2017;45(W1):W98-W102.

16. Gyorffy B, Lánczky A, Szállási Z. Implementing an online tool for genome-wide validation of survival-associated biomarkers in ovariancancer using microarray data from 1287 patients. Endocr Relat Cancer. 2012;19(2):197-208.

17. Cerami E, Gao J, Dogrusoz U, et al. The cBio cancer genomics portal: an open platform for exploring multidimensional cancer genomics data. Cancer Discov. 2012;2(5):401-404.

18. Montojo J, Zuberi K, Rodriguez H, Bader GD, Morris Q. GeneMANIA: fast gene network construction and function prediction for Cytoscape. F1000Res. 2014;3:153.

19. Huang da W, Sherman BT, Lempicki RA. Systematic and integrative analysis of large gene lists using DAVID bioinformatics resources. Nat Protoc. 2009;4(1):44-57.

20. Huang da W, Sherman BT, Lempicki RA. Bioinformatics enrichment tools: paths toward the comprehensive functional analysis of large gene lists. Nucleic Acids Res. 2009;37(1):1-13.

21. Hendrix ND, Wu R, Kuick R, Schwartz DR, Fearon ER, Cho KR. Fibroblast growth factor 9 has oncogenic activity and is a downstream target of Wnt signaling in ovarian endometrioid adenocarcinomas. Cancer Res. 2006;66(3):1354-1362.

22. Adib TR, Henderson S, Perrett C, et al. Predicting biomarkers for ovarian cancer using gene-expression microarrays. Br J Cancer. 2004;90(3): 686-692.

23. Lu KH, Patterson AP, Wang L, et al. Selection of potential markers for epithelial ovarian cancer with gene expression arrays and recursive descent partition analysis. Clin Cancer Res. 2004;10(10): $3291-3300$. 
24. Yoshihara K, Tajima A, Komata D, et al. Gene expression profiling of advanced-stage serous ovarian cancers distinguishes novel subclasses and implicates ZEB2 in tumor progression and prognosis. Cancer Sci. 2009;100(8):1421-1428.

25. Khelwatty SA, Essapen S, Seddon AM, Modjtahedi H. Prognostic significance and targeting of HER family in colorectal cancer. Front Biosci (Landmark Ed). 2013;18:394-421.

26. Montemurro F, Scaltriti M. Biomarkers of drugs targeting HER-family signalling in cancer. J Pathol. 2014;232(2):219-229.

27. Moorcraft SY, Chau I. Investigational therapies targeting the ErbB family in oesophagogastric cancer. Expert Opin Investig Drugs. 2014;23(10): 1349-1363.

28. Reyes HD, Thiel KW, Carlson MJ, et al. Comprehensive profiling of EGFR/HER receptors for personalized treatment of gynecologic cancers. Mol Diagn Ther. 2014;18(2):137-151.

29. Mehner C, Oberg AL, Goergen KM, et al. EGFR as a prognostic biomarker and therapeutic target in ovarian cancer: evaluation of patient cohort and literature review. Genes Cancer. 2017;8(5-6):589-599.

30. Sasaki T, Hiroki K, Yamashita Y. The role of epidermal growth factor receptor in cancer metastasis and microenvironment. Biomed Res Int. 2013;2013:546318-8.

31. Liu X, Feng C, Liu J, et al. The importance of EGFR as a biomarker in molecular apocrine breast cancer. Hum Pathol. 2018;77:1-10.

32. Corcoran RB, André T, Atreya CE, et al. Combined $B R A F$, EGFR, and $\mathrm{MEK}$ inhibition in patients with $B R A F^{\mathrm{V} 600 \mathrm{E}}$-mutant colorectal cancer. Cancer Discov. 2018;8(4):428-443.

33. Wang YN, Lee HH, Chou CK, et al. Angiogenin/ribonuclease 5 Is an EGFR ligand and a serum biomarker for erlotinib sensitivity in pancreatic cancer. Cancer Cell. 2018;33(4):752-769.

34. Schwanhäusser B, Busse D, Li N, et al. Global quantification of mammalian gene expression control. Nature. 2011;473(7347):337-342.

35. Skirnisdóttir I, Sorbe B, Seidal T. The growth factor receptors HER-2/ neu and EGFR, their relationship, and their effects on the prognosis in early stage (FIGO I-II) epithelial ovarian carcinoma. Int J Gynecol Cancer. 2001;11(2):119-129.

36. Wang K, Li D, Sun L. High levels of EGFR expression in tumor stroma are associated with aggressive clinical features in epithelial ovarian cancer. Onco Targets Ther. 2016;9:377-386.

37. de Graeff P, Crijns AP, Ten Hoor KA, et al. The ErbB signalling pathway: protein expression and prognostic value in epithelial ovarian cancer. $\mathrm{Br}$ J Cancer. 2008;99(2):341-349.

38. de Graeff P, Crijns AP, de Jong S, et al. Modest effect of p53, EGFR and HER-2/neu on prognosis in epithelial ovarian cancer: a meta-analysis. Br J Cancer. 2009;101(1):149-159.

39. Perez EA, Cortés J, Gonzalez-Angulo AM, Bartlett JM. HER2 testing: current status and future directions. Cancer Treat Rev. 2014;40(2):276-284.

40. Wolff AC, Hammond ME, Hicks DG, et al. Recommendations for human epidermal growth factor receptor 2 testing in breast cancer: American Society of Clinical Oncology/College of American Pathologists clinical practice guideline update. J Clin Oncol. 2013;31(31):3997-4013.
41. Ballinger TJ, Sanders ME, Abramson VG. Current HER2 testing recommendations and clinical relevance as a predictor of response to targeted therapy. Clin Breast Cancer. 2015;15(3):171-180.

42. Rakha EA, Pigera M, Shaaban A, et al. National guidelines and level of evidence: comments on some of the new recommendations in the American Society of Clinical Oncology and the College of American Pathologists human epidermal growth factor receptor 2 guidelines for breast cancer. J Clin Oncol. 2015;33(11):1301-1302.

43. Tanner B, Kreutz E, Weikel W, et al. Prognostic significance of c-erB-2 mRNA in ovarian carcinoma. Gynecol Oncol. 1996;62(2): 268-277.

44. Meden H, Kuhn W. Overexpression of the oncogene c-erbB-2 (HER2/ neu) in ovarian cancer: a new prognostic factor. Eur J Obstet Gynecol Reprod Biol. 1997;71(2):173-179.

45. Tomić S, Ilić Forko J, Babić D, Sundov D, Kuret S, Andelinović S. c-erbB-2, p53, and nm 23 proteins as prognostic factors in patients with epithelial ovarian carcinoma. Croat Med J. 2003;44(4):429-434.

46. Luo H, Xu X, Ye M, Sheng B, Zhu X. The prognostic value of HER2 in ovarian cancer: a meta-analysis of observational studies. PLoS One. 2018;13(1):e0191972.

47. Wang Z. ErbB receptors and cancer. Methods Mol Biol. 2017;1652: 3-35.

48. Zhang N, Chang Y, Rios A, An Z. HER3/ErbB3, an emerging cancer therapeutic target. Acta Biochim Biophys Sin (Shanghai). 2016;48(1): $39-48$.

49. Nielsen TO, Friis-Hansen L, Poulsen SS, Federspiel B, Sorensen BS. Expression of the EGF family in gastric cancer: down regulation of HER4 and its activating ligand NRG4. PLoS One. 2014;9(4): e94606.

50. Hamburger AW. The role of ErbB3 and its binding partners in breast cancer progression and resistance to hormone and tyrosine kinase directed therapies. J Mammary Gland Biol Neoplasia. 2008;13(2): 225-233.

51. Tanner B, Hasenclever D, Stern K, et al. ErbB-3 predicts survival in ovarian cancer. J Clin Oncol. 2006;24(26):4317-4323.

52. Ma J, Lyu H, Huang J, Liu B. Targeting of erbB3 receptor to overcome resistance in cancer treatment. Mol Cancer. 2014;13:105.

53. Mujoo K, Choi BK, Huang Z, Zhang N, An Z. Regulation of ERBB3/ HER3 signaling in cancer. Oncotarget. 2014;5(21):10222-10236.

54. Muraoka-Cook RS, Feng SM, Strunk KE, Earp HS. ErbB4/HER4: role in mammary gland development, differentiation and growth inhibition. J Mammary Gland Biol Neoplasia. 2008;13(2):235-246.

55. Hollmén M, Elenius K. Potential of ErbB4 antibodies for cancer therapy. Future Oncol. 2010;6(1):37-53.

56. Wali VB, Gilmore-Hebert M, Mamillapalli R, et al. Overexpression of ERBB4 JM-a CYT-1 and CYT-2 isoforms in transgenic mice reveals isoform-specific roles in mammary gland development and carcinogenesis. Breast Cancer Res. 2014;16(6):501

57. Mishra R, Hanker AB, Garrett JT. Genomic alterations of ERBB receptors in cancer: clinical implications. Oncotarget. 2017;8(69): 114371-114392.
Cancer Management and Research

\section{Publish your work in this journal}

Cancer Management and Research is an international, peer-reviewed open access journal focusing on cancer research and the optimal use of preventative and integrated treatment interventions to achieve improved outcomes, enhanced survival and quality of life for the cancer patient. The manuscript management system is completely online and includes

\section{Dovepress}

a very quick and fair peer-review system, which is all easy to use. Visit $\mathrm{http}: / / \mathrm{www}$.dovepress.com/testimonials.php to read real quotes from published authors. 